\title{
Mercury electrode as a tool/sensor for pollutants monitoring in natural waters; advantages and disadvantages regarding moving to "green" electrochemistry
}

\begin{abstract}
Electrochemical measurements are the most used and challenging approaches in trace elements analysis and speciation in complex natural samples. There is a wide research community that used electrochemical methods for studying critical environmental and biogeochemical processes, both natural and anthropogenically perturbed, that influence ecosystem services and human health. In recent years more attention is focused on development of environmentally friendly and sustainable chemical processes and tools which have aim to reduce negative footprint on the environment. Development in the electrochemistry is heading in this "green" direction, since EU regulations confined use of mercury, which has been established as the preferred tool/ sensor in electrochemical measurements. Therefore, development of new and more environmentally safely electrode materials is imperative. In this mini-review we discuss advantages of the mercury electrode use in measurements of organic material with surface active properties and sulfur compounds in natural waters.
\end{abstract}

Volume 4 Issue 3 - 2018

Ciglenečki I, Marguš M, Orlović-Leko P
Ruder Bošković Institute, Croatia

Correspondence: Ciglenečki I, Division for Marine and Environmental Research, Ruđer Bošković Institute, Bijenička 54, 10000 Zagreb, Croatia, Email irena@irb.hr

Received: April 19, 2018 | Published: May 04, 2018

Keywords: electrochemistry, voltammetry, $\mathrm{Hg}$ electrode, pollutants, chemical speciation, natural waters, green electrochemistry

\section{Introduction}

Green Chemistry or Sustainable Chemistry is defined by the $\mathrm{EPA}^{1}$ as "the design of chemical products that reduce or eliminate the use of hazardous substances". In recent years there are great expectations that chemists will produce greener and more sustainable chemical processes. In this direction, relevant benefits from "green" electrochemical activities (better control, higher selectivity, safer operations, milder conditions, and the use of electrons as a cheap reagent) were found. Some important instances of "green" electrochemistry are detectors and bio-detectors for environmental analysis (detection of pollutants). Since the invention of polarography, the $\mathrm{Hg}$ electrode was established as the preferred electrode for use in electrochemistry due to the high over potential for hydrogen evolution (which enables work at moderately negative potentials), as well as renewability of the electrode surface. ${ }^{2}$ The current trend of "green" chemistry, that encourages avoiding the use and generation of toxic substances, as well as recent EU regulations that have prohibited exporting and storing metallic $\mathrm{Hg}$, have led to the search of competitive electrodes fabricated with minimal amount of $\mathrm{Hg}$ or definitely with other materials. However, in comparison to solid electrodes, $\mathrm{Hg}$ has many advantages which cannot easily be ignored and replaced in the move towards "green" electrochemistry by use of solid electrodes when characterizing the surface active (SA) fraction of organic matter as well as sulfur species in natural waters. ${ }^{2-6}$

There is a wide range of electroanalytical techniques which use the mercury electrode as a working electrode for possible qualitative and quantitative determination of pollutants in natural waters (potentiometry, polarography, voltammetry, chronopotentiometry, chronoamperometry etc.). ${ }^{7,8}$ These electrochemical methods, especially voltammetry, have appropriate features to be used as monitoring methods (early warning tools) for aqueous systems in general and are among key methods for analyses of hydrophobic and surface active organic compounds ${ }^{2-4}$, sulphur species, ${ }^{5,10-16}$ trace metals, ${ }^{8,17-22}$ engineered and natural nanoparticles. ${ }^{13-16,23-25}$. Voltammetry is the only technique allowing determination and chemical speciation (oxido-reduction state, the presence of different species) of the truly dissolved and particulate inorganic and organic species without any sample handling. Given that voltammetry provides information about relationship and reactivity between different chemical species in natural waters. So we can say that it allows monitoring the interaction between chemistry, biology, physics, and/or it provides answer how chemistry affects biology and ecology, and/or how living organisms change the chemistry of the environment where they live. ${ }^{6,9,21,26}$ Thus, electrochemical measurements in natural waters are essential in order to obtain more complete speciation information and to fully understand the geochemical cycling and bioavailability (toxicity) of elements. To fulfill this mission it is mandatory to have enough sensitive working electrodes, i.e. voltammetric sensors, with embodiments that make them specific for detection of natural and anthropogenically introduced compounds in natural environment.

\section{Discussion}

Electrochemical methods that have been applied in our group in the last 50 years enables quantification of different type of organic matterial with surface active properties, organic and inorganic sulfur compounds (reduced sulfur species,RSS), natural and engeenered nanoparticles in model and different natural water samples (urban and marine atmosphere, sea- and freshwater systems, drainage water from agriculture area, mining water). Developed methodology offers insight into spatial distribution and seasonal variations of surface active substances (SAS) ${ }^{3,4,27-29}$ and RSS $^{6,9,10,13,27}$ in the water environment. 
Curve shape analysis (Figure 1) enables rough characterization of predominant SAS groups (more hydrophobic and/or hydrophilic types, from saturated fatty acids, polysaccharide xanthan, fulvic and humic type of material), ${ }^{6,4,27,29}$ while oxido-reduction peaks offer information on presence of analytes that are oxydized and/or reduced at the $\mathrm{Hg}$ surface, ${ }^{4,5,12-16}$ (Figure 2). A detailed analysis of results from both approaches gives information about the composition of the investigated samples, and prevailing type of organic material..$^{3,4,27,29}$

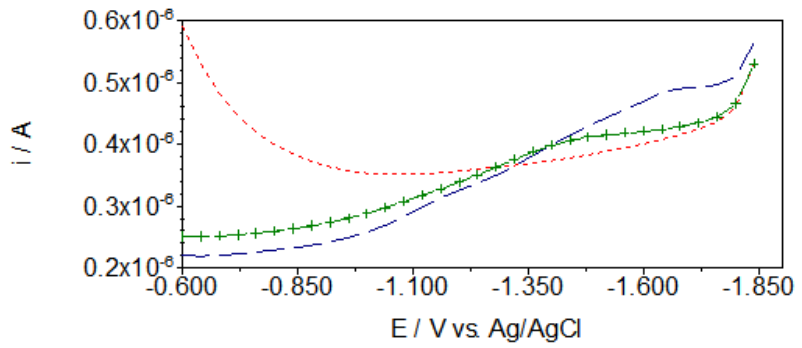

Figure I AC voltammetric curves of non-filtered,NF (dashed blue) and filtered, $F$ (green crosses) samples taken in spring season from drainage basin in the wetland area of Lonja field (Croatia). ${ }^{4}$ Desorption peak around - I.6V in the NF sample (FIGURE I)can be ascribed to the presence of polysacharide type of organic matter ${ }^{3}$. Please note that majority of this material was removed by filtration through 0.45 um filter. Dotted red curve corresponds to electrolyte $(0.55 \mathrm{M} \mathrm{NaCl})$.All curves are recorded after $120 \mathrm{~s}$ accumulation time (with stirring of the solution) at the deposition potential of $-0.6 \mathrm{~V}$ at the hanging $\mathrm{Hg}$ drop electrode. All potentials were measured against the $\mathrm{Ag} / \mathrm{AgCl}$ reference electrode while graphite rod was the counter electrode.

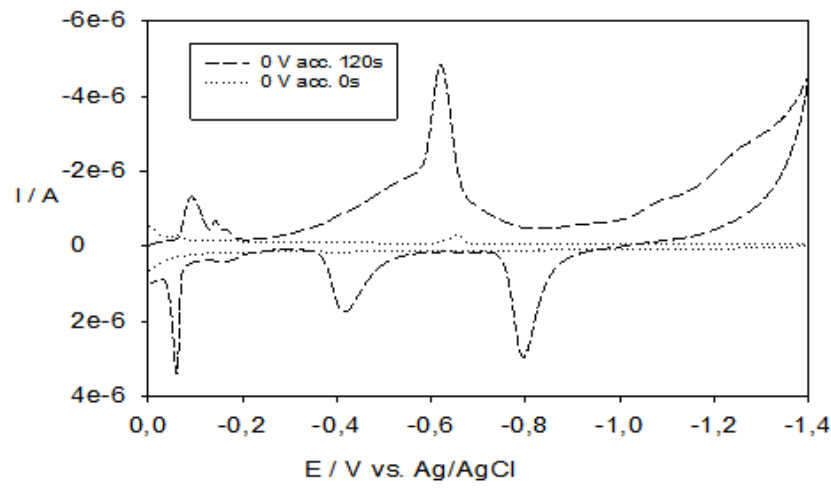

Figure 2 Cyclic voltammetric (CV) curves of seawater peloid sediment suspension at the hanging $\mathrm{Hg}$ drop electrode. Cathodic going scan without accumulation (dotted line) and after 120 s of accumulation (dash line) at $\mathrm{E}_{\text {acc }}=$ $0 \mathrm{~V}$. Scan rate $=100 \mathrm{mV} / \mathrm{s}$. Reduction peak at around $-0.6 \mathrm{~V}$ corresponds to the presence of sulfur species recovered by $\mathrm{HgS}$ reduction, ${ }^{6,10}$ while anodic peaks at around -0.8 and $-0.4 \mathrm{~V}$ correspond to the presence of Fe. ${ }^{14-16}$ Please note that all peaks were recovered by longer accumulation time at the starting potential. All potentials were measured against the $\mathrm{Ag} / \mathrm{AgCl}$ reference electrode; graphite rod was the counter electrode.

\section{Conclusion}

$\mathrm{Hg}$ electrode is a simple and very practical model of a charged interface while solid electrodes resemble natural interfaces more closely, especialy for the study of adsorption processes and surface active substances measurements. ${ }^{30,31}$ In comparisson with $\mathrm{Hg}, \mathrm{Au}$ electrode has stabile structure which is more sensitive on the way of electrode preparation, applied potentials, composition of the solution, and temperature. ${ }^{29,30}$ Comparative measurements of sulfide at the $\mathrm{Hg}$ and $\mathrm{Au}$ electrodes showed different sensitivity and selectivity of the $\mathrm{Hg}$ surface for such type of compounds. Besides, advantages of smooth and reproducible renewable surface of the $\mathrm{Hg}$ electrode have been evidenced in analytical procedures based on both faradaic and nonfaradaic processes. Nevertheless, in our measurements and water quality monitoring we have not yet found an adequate and more „green“ replacement for the $\mathrm{Hg}$ electrode.

\section{Acknowledgements}

This work is supported by the project "The Sulphur and Carbon Dynamics in the Sea and Fresh-Water environment" (IP-11-20131205 SPERE).

\section{Conflict of interest}

Authors declares that there is no conflict of interest.

\section{References}

1. Green Chemistry.

2. Ćosović B, Kozarac Z, Frka S, et al. Electrochemical Adsorption Study of Natural Organic Matter in Marine and Freshwater Systems. A Plea for Use of Mercury for Scientific Purposes. Electroanalysis. 2010;22(17-18):1994 2000.

3. Ćosović B, Vojvodić V. Voltammetric analysis of surface active substances in natural seawater. Electroanalysis. 1998;10:429-434.

4. Orlović-Leko P, Vidović K, Plavšić M, et al. Voltammetry as a tool for rough and rapid characterization of dissolved organic matter in the drainage water of hydroameliorated agricultural areas in Croatia. $J$ Solid State Electrochem. 2016;20:3097-3105.

5. Ciglenečki, Ćosović B. Electrochemical Determination of Thiosulfate in Seawater in the Presence of Elemental Sulfur and Sulfide. Electroanalysis. 1997;9:775-780.

6. Bura-Nakić, Helz GR, Ciglenečki I, et al. Seasonal variations in reduced sulfur species in a stratified seawaterlake (Rogoznica Lake, Croatia): evidence for organic carriers of reactive sulfur. Geochim Cosmochim Acta. 2009; 73:3738-3751.

7. Rajeshwar K, Ibanez JG. Environmental Electrochemistry. Academic Press: San Diego; CA. 1997.

8. Buffle J, Tercier-Waeber ML. Voltammetric environmental trace metal analysis and speciation: from laboratory to in situ measurements. Trends Anal Chem. 2005;24:172-191.

9. Luther GW, Giblin A E, Varsolona R. Polarographic analysis of sulfur species in marine porewaters. Limnol Oceanogr. 1985;30:727-736.

10. Batina N, Ciglenečki I, Ćosović B. Determination of elemental sulphur, sulphide and their mixtures in electrolyte solutions by a.c. voltammetry. Anal Chim Acta. 1992;267:157-164.

11. Davison W, Buffle J, De Vitre RR. Voltammetric characterization of a dissolved iron sulfide species by laboratory and field studies. Anal Chim Acta. 1998;77:193-203.

12. Ciglenečki I, Ćosović B, Ciglenečki I, et al. Electrochemical Study of Sulfur Species in Seawater and Marine Phytoplankton Cultures. Mar Chem. 1996;52:87-97.

13. Ciglenečki I, Krznarić D, Helz GR. Voltammetry of copper sulfide particles and nanoparticles: Investigation of the cluster hypothesis. Environ $\mathrm{Sci}$ Technol. 2005;39:7492-7498. 
14. Bura-Nakić B, Viollier E, Ciglenečki I. Electrochemical and colorimetric measurements show the dominant role of $\mathrm{FeS}$ in a permanently anoxic lake. Environ Sci Technol. 2013;47: 741-749.

15. Bura-Nakić B, Krznarić D, Jurašin D, et al. Voltammetric characterization of metal sulfide particles and nanoparticles in model solutions and natural waters. Anal Chim Acta. 2007;94: 44-51.

16. Milanović I, Krznarić D, Bura-Nakić E, et al. Deposition and dissolution of metal sulfide layers at the $\mathrm{Hg}$ electrode surface in seawater electrolyte conditions. Environ Chem. 2014;11: 167-172.

17. Tercier ML, Buffle J, Zirino A, et al. In situ voltammetric measurement of trace elements in lakes and oceans. Anal Chim Acta. 1990;237:429-437.

18. Achterberg EP, Braungardt C. Stripping voltammetry for the determination of trace metal speciation and in-situ measurements of trace metal distributions in marine waters. Anal Chim Acta. 1999;400:381-397.

19. Taillefert M, Luther GW III, Nuzzio DB. The application of electrochemica tools for in situ measurements in aquatic systems. Elecroanalysis. 2000;12:401-412.

20. Pižeta I, Billon G, Fisher JC, et al. Solid electrodes for in situ voltammetric measurements. Electroanalysis. 2003;15(17):1389-1396.

21. Luther GW, Glazer B, Ma S, et al. Iron and sulfur chemistry in a stratified lake: Evidence for iron rich sulfide complexes. Aquatic Geochem 2003;9:87-110

22. Braungardt CB , Achterberg E, Axelsson B, et al. Analysis of dissolved metal fractions in coastal waters: An inter-comparison of five voltammetric in situ profiling (VIP) systems. Mar Chem. 2009;114:47-55.

23. Marguš M, Batina N, Ciglenečki I. The development of electrochemical methods for determining nanoparticles in the environment. Part I. Voltammetry and in-situ electrochemical scanning tunnelling microscopy
(EC-STM) study of FeS in sodium chloride solutions. Environ Chem. 2014;11:181-186.

24. Bura-Nakić E, Marguš M, Milanović I, et al. The development of electrochemical methods for determinimg nanoparticles in the environment. Part II. Chronoamperometric study of FeS in sodium chloride solutions. Environ Chem. 2014;11:187-195.

25. Zhou Y, Rees NV, Pillay J, et al. Gold nanoparticles show electroactivity: counting and sorting nanoparticles upon impact with electrodes. Chem Commun. 2012;48:224-226.

26. Luther GW III, Glazer BT, Ma S, et al. Use of voltammetric solid-state (micro)electrodes for studying biogeochemical processes: laboratory measurements to real time measurements with an in situ electrochemical analyser (ISEA). Mar Chem. 2008;08:221-235.

27. Marguš M, Morales-Reyes I, Bura-Nakić E, et al. The anoxic stress conditions explored at the nanoscale by Atomic Force Microscopy in highly eutrophic and sulfidic marine lake. Contl Shelf Res. 2015;109:24-34.

28. Gašparović B (2012) Decreased production of surface-active organic substances as a consequence of the oligotrophication in the Northern Adriatic Sea. Estuar Coast Shelf Sci. 115: 33-39.

29. Frka S, Dautović J, Kozarac Z, et al. Surface-active substances in atmospheric aerosol: an electrochemical approach. Tellus B. 2012;64:18490-18502.

30. Krznarić D, Goričnik T, Ćosović B. Electrochemical Determination of Organic Surface Active Substances in Model and Natural Sea Water with Au(111) Monocrystal Electrode. Croat Chem Acta. 2000;73:247-261.

31. Krznarić D, Goričnik T, Vuković M, et al. Humic Acid Adsorption on the $\mathrm{Au}(111)$ and $\mathrm{Au}$ Polycrystalline Electrode. Electroanalysis. 2001;13:109116. 